\title{
O CASO CLÁSSICO DO NAVIO LOTUS À LUZ DA GIÊNCIA MODERNA
}

\author{
José Roberto Franco da Fonseca \\ Professor Associado do Departamento de Direito Internacional da \\ Faculdade de Direito da Universidade de São Paulo
}

Resumo:

O caso relativo ao navio Lotus foi submetido à Corte Permanente de Justiça Internacional numa época em que o direito criminal e o processual penal ainda não tinham pleno desenvolvimento científico.

Hoje, todavia, esse tema deve ser estudado à luz da moderna teoria dos conflitos de leis processuais.

\begin{abstract}
:
The lawsuit concerning the ship Lotus was submitted to the Permanent Court of International Justice in a time when criminal and procedural law were not entirely been developed by science.

Nowadays, however, this matter should be studied under the approach of modern theory of conflict of procedure laws.
\end{abstract}

\section{Introdução}

1.1 - Prévia questão metodológica.

A eleição do tema não deve fazer supor filiação do autor à metodologia casuística ou indutiva, originada na Inglaterra e contrastada na Europa continental pelos dedutivistas, no âmbito do Direito Internacional. Ambos os métodos, a rigor, apresentam algumas inconveniências, havendo necessidade de sua conjugação, não sem que daí decorra o fato de indução ou dedução virem, isoladamente, a prevalecer uma sobre a outra forma de juízo (Marotta Rangel, pp. 10-13), nesse esforço de conjugação. Sendo a regra jurídica síntese integrativa de fato, valor e norma, o método para sua apreensão não se reduzirá à mera indução nem à só dedução, senão transcenderá a ambas as formas de juízo (Miguel Reale, passim).

A eleição do tema deveu-se a outras circunstâncias metodológicas. É que, tendo sido o caso do navio Lotus julgado em 7 de setembro de 1927 pela Corte Permanente de Justiça Internacional, decidido por voto de desempate do presidente do colegiado e tendo suscitado longa discussão e controvérsia na doutrina, merece aqui 
reapreciado, à luz dos princípios, só mais tarde formulados às vezes ou só mais tarde consolidados na Alemanha e Itália, da Teoria Geral do Direito Penal e da Teoria Geral do Processo Penal.

\section{2 - Precisões terminológicas.}

Na apreciação do caso, assim os julgadores como os doutrinadores que o comentaram usam, às vezes sem rigor técnico ou científico, termos de conteúdo equívoco (do ponto de vista lógico) que só mais tarde a ciência penal e, mais inequivocamente, a processualística vieram aclarar e precisar. Acresce que os internacionalistas, de um modo geral, costumam empregar terminologia que nem sempre se adequa à da teoria geral moderna do Direito, talvez pelo fato de o Direito Internacional achar-se fortemente impregnado do impacto socio-cultural e político dos fatos dinâmicos que imprimem sua marca ao macrossistema das relações internacionais.

\section{Assim ocorre quanto ao termo jurisdição.}

Embora tenha o termo a acepção técnica de função do Estado, de caráter substitutivo em relação às partes, de atuação da verdade concreta da lei com o escopo de composição de litígios, os internacionalistas anglo-norte-americanos e os franceses usam-no no sentido equivalente ao de soberania (que, mais abrangente quanto à extensão, compreende o exercício com exclusividade das funções legislativa, administrativa e jurisdicional). Quando querem se referir à jurisdição em sentido estritamente técnico, os ingleses usam a locução "judicial jurisdiction" (Hudson, p. $20 \mathrm{e}$ ss.).

Assim ocorre, também, com o termo competência.

Embora no sentido técnico sua acepção seja a de limites (objetivos, subjetivos ou funcionais, geográficos) ao exercício de uma das funções do Estado (no caso concreto, limites da jurisdição), o termo é empregado não-raramente como designativo do próprio poder (considerado sem limites, em sua extensão lógica). Tal equivocidade não é tão grave, pois se pode discutir a validade de tal variação, muito embora fosse preferivel o rigor lógico aplicável à ciência jurídica.

1.3 - Precisões quanto ao objetivo temático, suscitado pelo caso em exame.

O caso clássico do navio Lotus pode suscitar dupla indagação teórica, adstrita ao campo do Direito Internacional, assim como outras indagações, que se 
devem circunscrever ao âmbito da Teoria Geral do Direito Penal, por um lado, e da Teoria Geral do Direito Processual Penal, por outro lado.

No âmbito do Direito Internacional, o duplo problema suscitado está relacionado com a existência (que pode ser monística ou dualisticamente apreciada) de um ordenamento jurídico da sociedade internacional e de um ordenamento jurídico interno de cada Estado-membro daquela sociedade. Tal existência (ou co-existência) leva à necessidade teórica e prática de estabelecer as lindes (competência internacional): a. da legislação substantiva penal; b. da jurisdição penal dos diversos Estados. Veremos, mais adiante, que tal duplo problema, na verdade, irá reduzir-se (v. infra, 1.4) a uma única verdadeira questão: a da distribuição internacional da jurisdição penal (dado o princípio da territorialidade da lei penal).

Tal é o objetivo deste nosso estudo. Ficam excluídas, pois, as demais indagações acima referidas, específicas do âmbito teórico do Direito substantivo Penal e do Direito Processual Penal, a não ser quanto aos aspectos intimamente ligados à solução do problema acima equacionado. Tais indagações são as que dizem respeito à possibilidade de co-autoria em crime culposo (hoje pacificamente admitida), à diferença entre co-autoria em crime culposo e culpas concorrentes (em que as ações são diferentes, mas concorrem ou convergem para a produção do evento), o problema natureza unitária ou pluralística desses crimes.

1.4 - Conclusões metodológicas: os verdädeiros termos do problema.

De tudo quanto se aduziu a título introdutório, deflui que o equacionamento do problema suscitado pelo caso estudado, para se permanecer no âmbito do Direito Internacional, reduz-se à questão da divisão internacional (limites, ou competência) das jurisdições estatais. Determinado o Estado ao qual se atribue a jurisdição criminal (para um fato delituoso que, em tese, possa interessar a mais de uma jurisdição possível), esgota-se a solução (uma vez que, quanto à lei penal substantiva aplicável, será a lei do foro).

Os fatores de complicação do problema, no caso concreto analisado, são vários, mas não chegam a desnaturar a verdadeira estrutura da equação, acima formulada. Tais complicadores começam pelo lugar esdrúxulo da consumação do delito: dois capitães, dirigindo cada um, um barco de uma bandeira diferente, agem, cada um deles, em ações diferentes mas convergentes para a produção do evento, com culpas concorrentes; do abalroamento, resultam mortes, a bordo só de um dos barcos, que vem a naufragar; sobrevivem ambos os capitães culpados e aportam em águas 
territoriais do Estado do pavilhão, que era ostentado pelo barco naufragado. Este último Estado arroga-se, fundado em suas leis processuais internas, o poder de jurisdição sobre o fato delituoso e condena os capitães.

\section{O Caso Lotus}

\subsection{A lide.}

Em 2 de agosto de 1926, no alto-mar, o capitão Demons, que comandava o barco Lotus, de pavilhão francês, agiu com culpa e abalroou o barco BezKourt, de pavilhão turco, cujo capitão, de nacionalidade turca, também agiu com culpa que concorreu para o naufrágio do seu barco e a morte de oito marinheiros e tripulantes turcos que nele se encontravam. O Lotus resgatou os náufragos sobreviventes, entre os quais o capitão turco, e foi aportar em Istambul. As autoridades processaram criminalmente e condenaram à pena privativa de liberdade; assim o capitão francês como o turco. Fizeram-no, fundadas em suas regras internas de: a. Direito Penal (art. $6^{\circ}$ ), que rezava que "o estrangeiro que cometer ofensa que possa prejudicar a Turquia ou um súdito turco (...) será punido de acordo com o Código Penal turco, na condição de ser a prisão efetuada na Turquia"; b. Direito Processual Penal, que recomendava a unidade de procedimento no caso de conexão.

A França, exercendo o instituto da proteção diplomática (Rezek, pp. 275-284), protestou formalmente junto à Turquia e ambos os Estados, em 12 de outubro de 1926, acordaram em submeter a lide (de pretensão indenizatória) à Corte Permanente de Justiça Internacional.

Como fundamento principal de sua pretensão, a França alegava que a Turquia agira ilicitamente, tendo em vista terem ambos os Estados litigantes, ratificado o art. 16, da Convenção de Lausanne, de 24 de julho de 1923, que rezava: as questões de competência judicial nas relações entre a Turquia e as outras potências contratantes seriam reguladas conforme os principios do Direito Internacional. E, concluía a França, era princípio de Direito Internacional costumeiro o absterem-se reiteradamente os Estados de exercitar sua jurisdição criminal em matéria de abalroamento, deixando-a sistematicamente, para ser exercida pelo país da bandeira do barco em que ocorrem os danos. 


\section{2 - A decisão da CPJI.}

A decisão do Tribunal foi tomada por voto de desempate, proferido pelo juiz-presidente.

Quanto ao fundamento da pretensão francesa, decidiu-se que se a escassez de decisões judiciais criminais que se puder inferir das coleções de jurisprudência interna constituísse uma prova suficiente do princípio invocado pela França, o resultado lógico seria simplesmente o reconhecer que os Estados freqüentemente se abstiveram, de fato, de exercer a persecução penal que lhes incumbia, e não reconhecer que eles estivessem movidos por uma consciência de que tal abstenção lhes fosse obrigatória juridicamente (caso em que, sim, se poderia invocar um costume internacional).

De conseqüência, decidiu o tribunal que "o que se passa a bordo de um navio em alto-mar deve ser considerado como se tivesse ocorrido no território do Estado, cuja bandeira o navio usa. Se, pois, um ato delituoso, cometido num navio, em alto-mar, produz seus efeitos sobre um navio que usa outra bandeira ou sobre um território estrangeiro, devem ser aplicados ao caso os mesmos princípios que se aplicariam se se tratasse de dois territórios de Estados diferentes e, portanto, deve concluir-se que nenhuma regra de direito internacional proíbe ao Estado, de que depende o navio, onde os efeitos do delito se manifestaram, considerar esse delito como se tivesse sido cometido no seu território e exercer a ação penal contra o delinqüente" (Lotus, arrêt. n. 9, 1927, CPJI, série A, n. 10, pp. 25 e 28).

\section{3 - Opiniões divergentes. Apreciação crítica.}

Houve declarações de votos divergentes dos juízes Lader (Hudson, pp. 46-50), Weiss (idem, pp. 50-7), Lord Finlay (idem, pp. 57-62), Nyhelm (idem, pp. 625), Moore (idem, pp. 65-83 e Altamira (idem, pp. 83-91).

A leitura desses votos é interessante, posto que a discussão sobre seu conteúdo fuja aos propósitos deste sumário estudo. Isso ocorre porque o propósito de nossas considerações é a aplicação, ao caso clássico do navio Lotus, dos princípios consolidados na moderna teoria geral do Direito Penal e na moderna teoria geral do Direito Processual Penal, princípios que, à época do julgamento, se não encontravam, ainda, precisamente formulados doutrinariamente. Além do esforço de aplicação de tais princípios doutrinários, é pretensão do presente trabalho apontar as soluções que, 
posteriormente ao julgamento, vieram a ser dadas ao problema pelo Direito Internacional positivo, naquela época omisso.

Tais considerações doutrinárias e dogmáticas seguem-se nos ns. 4 e 5 infra (no que diz respeito à questão da "competência processual internacional"). É claro que tal exposição deve ser necessariamente precedida do estudo (feito no n. 3 infra) das relações entre o direito interno e o internacional (pois o problema reduz-se à divisão internacional de "competências" jurisdicionais).

Não se podem analisar, pois, quer a decisão da Corte quer os votos divergentes, à luz de princípios modernos, à época não-formulados com clareza nem transformados, ainda, em direito positivo no plano internacional.

\section{Direito Interno e Direito Internacional}

Para o estudo das relações entre a ordem jurídica interna e a internacional, é de mister, preliminarmente, se situe exatamente, dentro de um ou de outro dos sistemas, a regra definidora da competência processual penal dos Estados.

Ora bem, até a data do julgamento do caso Lotus e até algum tempo após tal data, não havia regra internacional (essa foi, ademais, a decisão da CPJI). As soluções eram dadas pelas normas de Direito Processual Penal Internacional (interno) dos Estados, tal como formuladas em seus códices de procedimentos.

A partir, porém, da Convenção de Bruxelas, de 23 de setembro de 1910, que dispunha sobre questões meramente atinentes à responsabilidade civil em caso de abalroamento, elaboraram-se regras, no ordenamento internacional, sobre jurisdição penal competente. Assim, a Convenção de Genebra sobre o alto-mar (assinada em 29 de abril de 1958) e a Convenção das Nações Unidas sobre o Direito do Mar (de Jamaica, 1982).

Diante disso, faz-se necessária tentativa de sistematização das teorias sobre a harmonização das ordens interna e internacional, no respeitante às regras determinadoras da jurisdição penal competente.

\section{1 - Doutrinas internacionalistas.}

Sustentam, com variantes, os internacionalistas que as regras internas de Direito Processual Penal Internacional, porque pressupõem concurso ou conflito de leis emanadas de diferentes Estados, são essencialmente integrantes de uma ordem jurídica supraestatal, internacional. Têm sua fonte original, objetiva e única, na organização 
jurídica da humanidade, decorrendo ou do renascido direito natural ou da imperiosidade da vida social dos povos e desenvolvendo-se num Direito Internacional das gentes, superior aos vários direitos subordinados, direitos internos.

Dentre os internacionalistas, os mais extremados são monistas. Outros há, nada obstante, dualistas, que admitem um direito interno e um das gentes, embora a fonte originária se situe no âmbito deste último. Destes, alguns afirmam o primado da ordem jurídica internacional: sustentam que as normas delimitadoras dos sistemas jurídicos coexistentes, como normas supraestatais de Superdireito (no sentido formulado por Zitelmann), se filiam ao direito das gentes, e este, ao criar a norma jurídica, cria a linha da sua competência, de modo que, na distribuição das competências, a comunidade supraestatal traça a superfície convexa, dentro da qual fica o branco preenchível pelo Estado. Tal é a interessante teoria de Pontes de Miranda (p. 72 , n. $43 ; 142$, ns. 128 e 129; e 143, n. 130). Para outros, a ordem jurídica estatal cria, por regras de Sobredireito, forma de elaboração do direito das gentes; assim, delega ou atribui competência, no exercício de uma verdadeira legislação de competência sobre competência.

\subsection{Doutrinas nacionalistas.}

Partindo do divortium acquarum, traçado por Triepel, entre o Direito Internacional e o direito interno, os nacionalistas sustentam, quanto às relações entre a ordem jurídica internacional e a interna, serem inteiramente diferentes esta e aquela (senão conflitantes às vezes), quanto às situações que regem e quanto às fontes de que promanam. A ordem jurídica interna rege relações ou somente entre indivíduos ou entre esses e o Estado; a ordem internacional rege aquelas entre Estados iguais, coordenados; a primeira promana da vontade de um Estado, manifestada na lei, enquanto a segunda decorre de consenso ou vontade coletiva dos Estados, expressa nos tratados ou no costume.

3.3 - Conclusões, Metodologia adequada.

Para bem situar-se a regra definidora da jurisdição criminal, no plano internacional, há que se estabelecer distinção entre categorias diversas de regras de Sobredireito.

Uma primeira categoria é a das regras de Direito Internacional Privado (indicativas de leis civis e comerciais aplicáveis a casos de natureza especial), as quais 
são nacionais, internas, de acordo com a concepção dualista nacionalista, acima sumariada. Só é concebível regra internacional, neste caso, na hipótese de tratado tendo por conteúdo a uniformização legislativa, continuando a matéria de direito interno por sua natureza.

Uma segunda categoria é a das regras de Direito Processual Internacional Criminal (indicativas do foro criminal competente). Nestas, a matéria é, por sua natureza, internacional. Pode prevalecer regra interna na inexistência de regra internacional (como decidido no caso Lotus); se existir regra internacional, esta prevalecerá.

O método, pois, consiste em analisar a natureza da matéria regulada pela regra de Sobredireito.

\section{Competência Processual Penal; Doutrina e Direito Interno Brasileiro}

\subsection{Princípio geral.}

Assim na doutrina como no direito positivo processual penal internacional, a regra é a de que a competência é do foro da consumação do delito. Exceção é aberta, no Direito brasileiro (Código de Processo Penal, art. 89), para os crimes cometidos a bordo de embarcações nacionais em alto-mar, que serão processados e julgados pela justiça do primeiro porto brasileiro em que tocar a embarcação, após o crime ou, quando se afastar do país, pela do último em que houver tocado. Tal exceção decorre do regime jurídico do navio em alto-mar, considerado extensão do território de sua bandeira e, portanto, só confirma a regra. Alternativa (art. 91): a prevenção.

\section{2 - Especificidades do caso Lotus.}

No caso em exame, todavia, para responder à questão sobre o lugar da consumação do delito, há especificidades decorrentes da própria estrutura do fato penal sub iudice. Tais especificidades são variáveis complicádoras, que podem ocorrer no caso dos chamados "crimes à distância" por um lado, e, por outro lado, no caso mais específico de abalroamento, em que há culpas concorrentes e resultados produzidos a bordo de uma das embarcações envolvidas.

Com relação aos crimes à distância (naus de pavilhões diferentes, navegando em espaço internacional), a "Exposição de motivos" do Código Penal de 
1940 esclarecia ter sido adotada a teoria da ubiqüidade (resultante da combinação da teoria da atividade e da teoria do efeito). O Código Penal brasileiro vigente, com a redação dada ao seu art. $6^{\circ}$ pela Lei n. 7.209 , de 11 de julho de 1984 , reitera que se considera "praticado o crime no lugar em que ocorreu a ação ou omissão, no todo ou em parte, bem como onde se produziu ou deveria produzir-se o resultado" Já Aníbal Bruno (pp. 225-6) considerava a teoria da ubiqüidade cientificamente correta, praticamente satisfatória na medida em que impede a inconveniência dos conflitos negativos de competência.

Mas o segundo fator de complicação, no caso do abalroamento analisado, está em duas outras especificidades, a saber: terem ambos os capitães (de naus de pavilhões diferentes) agido com culpa (negligência ou imprudência de um, imperícia de outro) e, mais, terem as mortes ocorrido no navio turco. Não se trata, pois, de co-autoria em crime culposo (caso em que haveria um único fato); mas, sim, de concorrência de fatos culposos, onde há dois fatos, embora o evento se tenha dado a bordo de uma das naus envolvidas.

Quanto à existência, no Direito Penal brasileiro, de regra (Cód. Penal, art. $7^{\circ}, \S 3^{\circ}$ ) que se poderia entender assemelhada à do art. $6^{\circ}$ do Código Penal turco, invocada no caso Lotus, tal fato é inteiramente irrelevante. É que essas regras dizem respeito à lei penal substantiva aplicável (no caso de a vítima ser de nacionalidade brasileira ou turca, respectivamente) e não ao foro competente. Sendo o Direito Penal eminentemente territorial, tais regras (porque pressupõem a entrada do criminoso no país ou sua prisão aí) são despiciendas, no que se refere à determinação do foro criminal competente. Não seria admissível o equívoco metodológico de indagar-se qual a lei substantiva aplicável, para daí inferir-se (por força da territorialidade da lei penal) qual o juizo competente, o que consistiria em violentação de qualquer lógica.

\section{Competência Processual Penal: Direito Internacional Positivo}

O principal fundamento da decisão da CPJI, no caso Lotus, consistiu em que tudo o que pode ser exigido de um Estado é que não ultrapasse os limites que o Direito Internacional impõe à sua jurisdição; dentro desses limites, seu título para o exercício da jurisdição repousa em sua soberania.

De feito, inexistia à época regra de Direito Internacional, quer convencional quer costumeira, sobre conflitos positivos de competência processual 
penal internacional. Entendeu a CPJI que tampouco foi provada a existência de qualquer princípio geral proibitivo da competência avocada pela legislação turca.

$\mathrm{O}$ fato é que, posteriormente, o Direito Internacional positivo passou a regular, especificamente, a matéria.

Assim, o art. 309 da Convenção de Direito Internacional Privado, assinada a 18 de fevereiro de 1928, em Havana (VI Conferência Interamericana), disporia que "nos casos de abalroamento culpável, em alto-mar ou no espaço aéreo, entre navios ou aeronaves de pavilhões diversos, aplicar-se-á a lei penal da vítima", silenciando, todavia, sobre o juízo competente. Depreender-se-á do art. 304 ("nenhum Estado contratante aplicará em seu território as leis penais dos outros") que o foro competente é também o da nacionalidade da vítima? Mas, e se as vítimas forem várias, de diversas nacionalidades? E que lei é a "da vítima": a da nacionalidade ou a do domicílio?

Já a Convenção de Bruxelas, de 10 de maio de 1952, tentou a unificação de regras relativas à competência criminal em matéria de abordagem, tendo sido derrogada pela Convenção assinada em Genebra, em 29 de abril de 1958, sobre o altomar, que assim dispõe no seu art. 11: "No caso de abalroamento ou qualquer outro incidente de navegação ocorrido a um navio em alto-mar e que possa acarretar a responsabilidade penal ou disciplinar do capitão, ou de qualquer outra pessoa a serviço do navio, nenhuma ação penal ou disciplinar pode ser intentada contra eles, a não ser perante as autoridades judiciais ou administrativas, seja do Estado da bandeira, seja do Estado da nacionalidade de tais pessoas" acrescentando $\left(\S 3^{\circ}\right)$ que "nenhum arresto ou detenção poderá ser decretado, mesmo para atos de instrução, por autoridades outras que não as do Estado do pavilhão", silenciando, quanto a estas medidas processuais penais cautelares, para a hipótese de pavilhões diversos.

Finalmente, a Convenção das Nações Unidas sobre o Direito do Mar, assinada em 1982, na Jamaica, transcreve, em seu art. 97, a mesma redação acima mencionada.

Ganham respaldo, pois, no Direito Internacional positivo, os arts. $89 \mathrm{e}$ 91, do Código de Processo Penal brasileiro. 
6. Bibliografia

BRUNO, Aníbal. Direito Penal. $2^{a}$ ed. Rio : Forense, 1956. v. I, t. I, p. 166.

CAMPOS, Barros Romeu Pires de. Direito Processual Penal Brasileiro. São Paulo :

Sugestões Literárias, 1969. v. I, p. 104-6.

HUDSON, Manley O. World Court Reports, Washington, 1935. v. II, p. 20.

JESUS, Damasio E. Direito Penal-Introdução e Parte Geral I. São Paulo : Bushatsky, 1972. t. I, p. 185-206.

MAROTTA RANGEL, Vicente. Direito e Relações Internacionais. $3^{\mathrm{a}}$ ed. São Paulo : Revista dos Tribunais, 1988, p. 9-16.

MIRANDA, Pontes de. Comentários à Constituição de 1946. $2^{\mathrm{a}}$ ed. São Paulo : Max Limonad, 1953. v. I.

REALE, Miguel. Filosofia de Direito. São Paulo : Saraiva, 1953. v.I.

REZEK, J.F. Direito Internacional Público. São Paulo : Saraiva, 1989.

SOARES, Guido F.S. O caso Lotus (material de classe, DDInt Fac. Dir.da USP).

VABRES, Donnedieu de. Introduction á L'étude du Droit Pénal International, Paris, 1922 